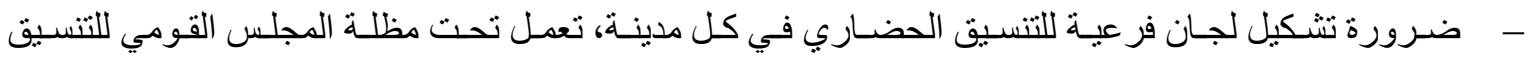

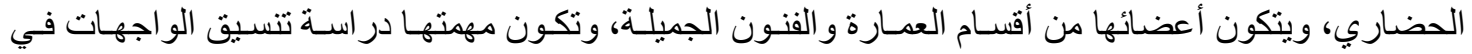
مختلف المناطق و اقتر اح البالتات و الخطط اللونية و المو اد المستخدمة لتكوين مشاهد عمر انية متناسقة.

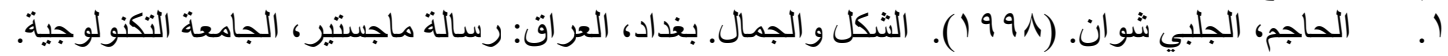
人

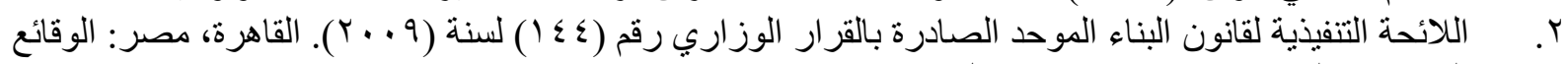

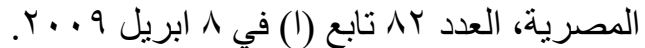

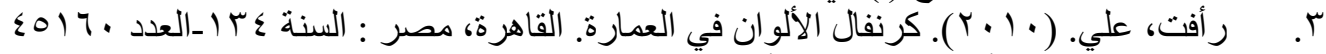

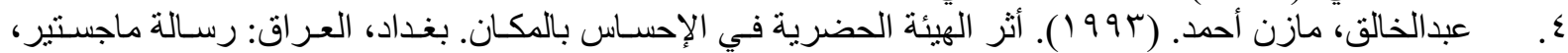

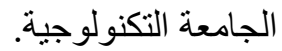

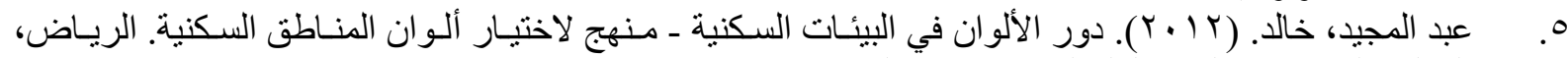

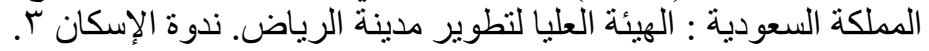

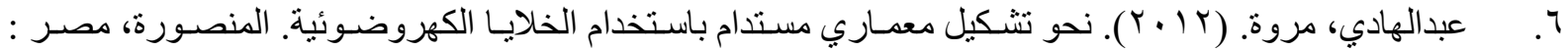

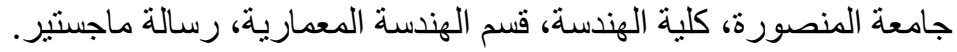

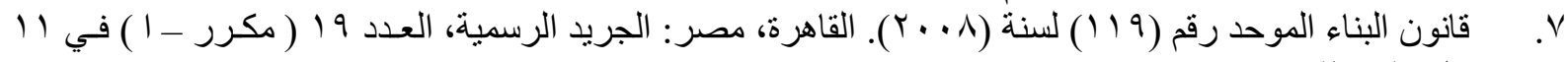

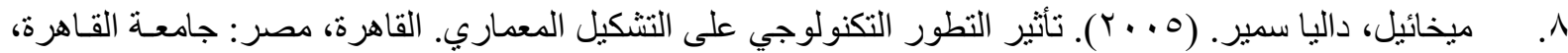
كلية الهندسة، قسم العمارة، رسالة ماجستير.

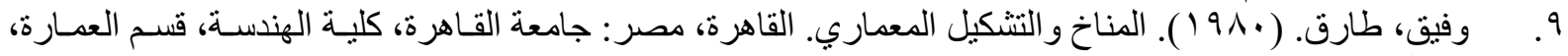
رسالة ماجستير.

\title{
المراجع الاجنبية
}

1. Arthur Gallion, Simon Eisner. (1963). The Urban Pattern. New York, W. D. Ten Broeck, USA : Second Edition

2. Elhady, Ibrahim \& Mohsen, Reham. (2013). Numerical harmony for natural colors related to human being. New Castle, United Kingdom : conference of the International Society of color

3. Ching Francis, D K. (1977). architecture form Space \& order. New York, USA: John Wiley \& Sons, Edition: 3

4. Arnheim, Rudolf. (1977). The Dynamics Of Architectural Form. London, United Kingdom : University of California Press. 
المناطق، وقد تناولت قوانين البناء عملية الألوان بصورة مبسطة لا تتناسب مع أهمية عنصر الألكوان، حيث تنـاول القـانون

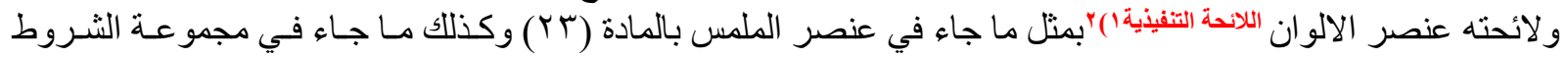

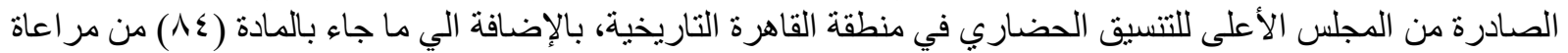

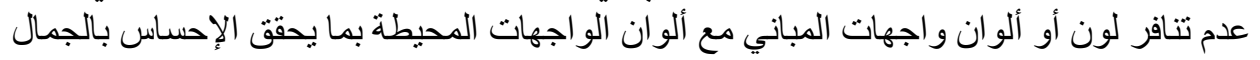
( النتائج و التوصيات ( ) أولا : النتائج

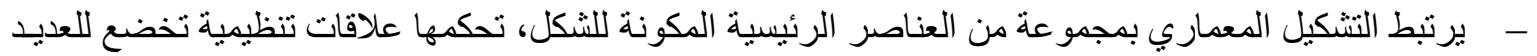

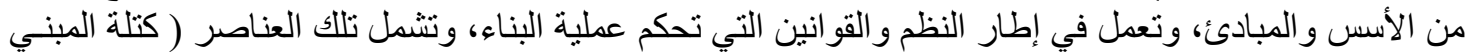

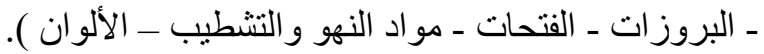

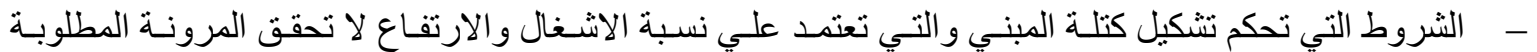

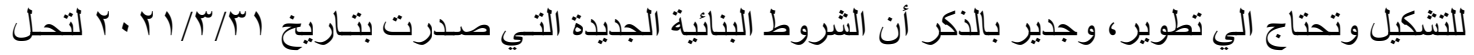

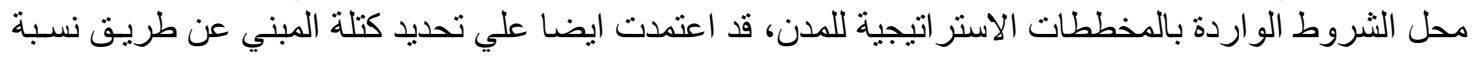
الإشغال (F.P) وارتفاع المبني، و هي بذللك لم تقدم جديدا في مجال التشكيل المعماري.

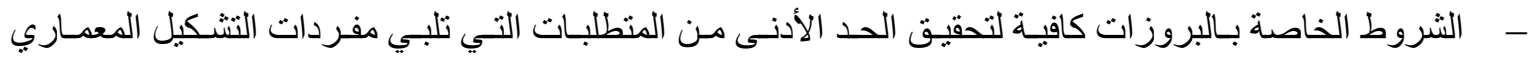
و المنفعة. - - الفتحات الو اردة بقانون البناء هي شروط مرنة لتحقيق التشكيل المطلاب في إطـار قـانوني يحـافظ علي عنصـر المنفحة.

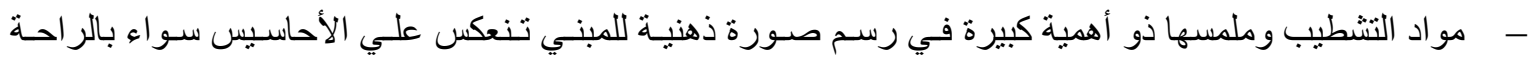

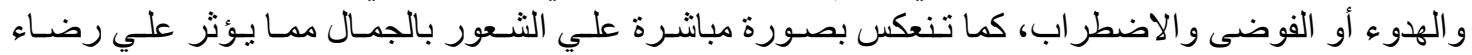

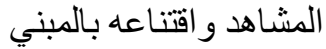
- عنصر الألوان ذو اهمية كبيرة في التشكيل لما له من قوة كامنة وقدرة هائلة علي تغيير ظاهر التكوينات و الأشـكال

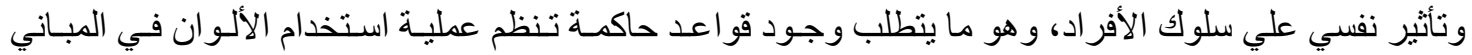

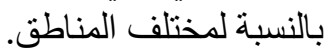

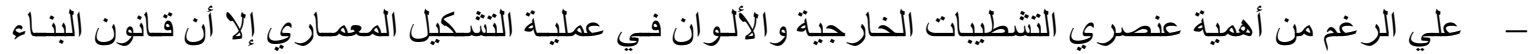
تناو لهما بطريقة هامشية لا تتناسب مع أهمية كل عنصر في تحقيق التشكيل المطلوب.

- - العمل علي تحديد كتلة المبني عن طريق تحويل الكثافـة السكانية المستهدفة باستخدام منوسط حجم الأسـرة إلـي

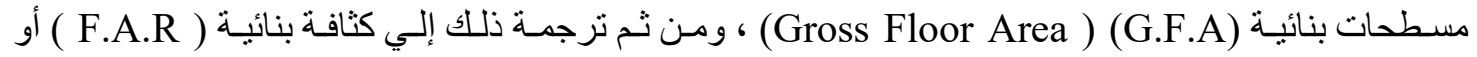

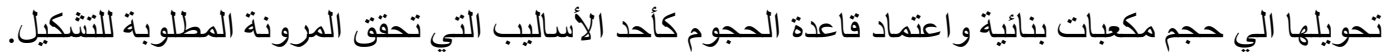

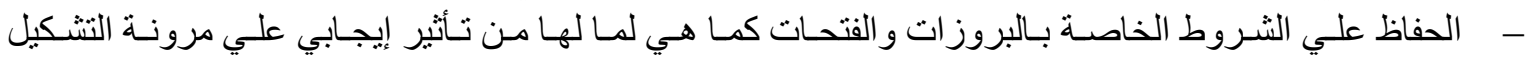
المعماري. - - تحتاج المو اد المستخدمة في التشطيبات الخارجية إلي بعض الثروط أو القيود التي تعمل علي ضبط أداء التشكيل

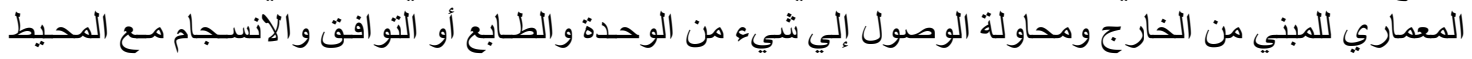
الخارجي للمبني.

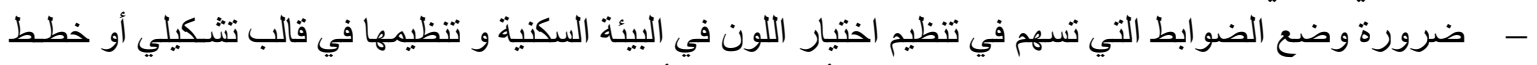
لونية للمناطق السكنية على مستوى الحي السكني أو المجاورة أو الثنار ع انتهاء بالمسكن. 


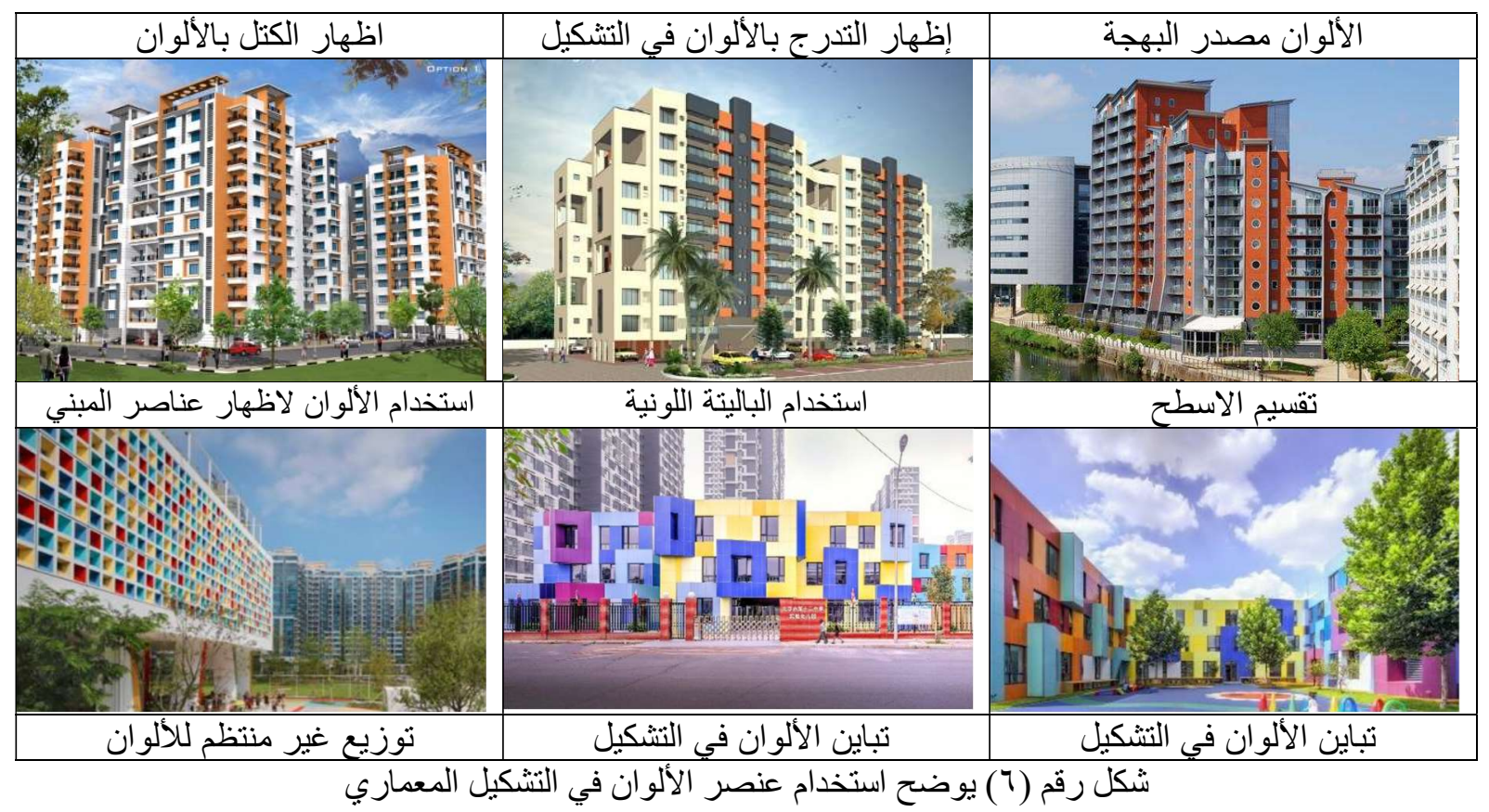

ويمكن الاستخدام الموجه للون أن يؤدي بعض الأدوار الهامة المتنوعة، والتي يمكن تصنيفها إلى أدوار موضو عية، وآخري

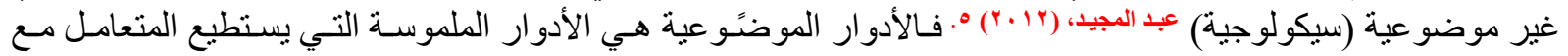

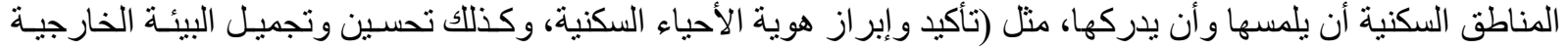

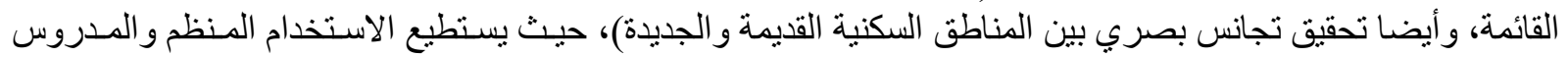

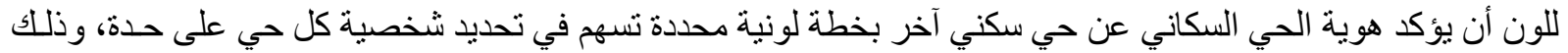
في غياب العناصر التشكيلية الأخرى التي قد تحقق طابعا مميز ا أو هوية عامة واضحة لكنة لكل حي، وكذللك تحسين المنساطق

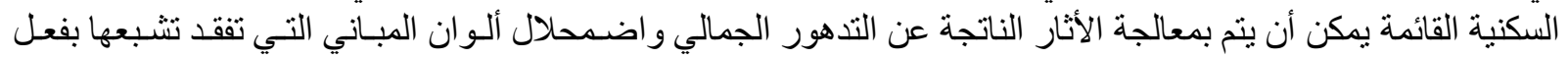

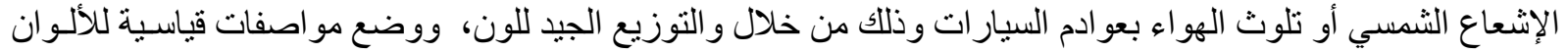

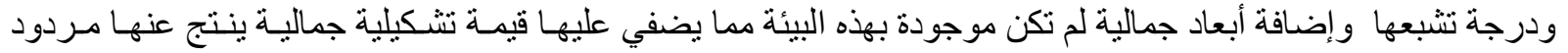

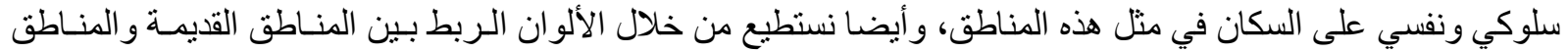

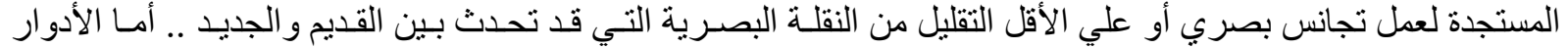

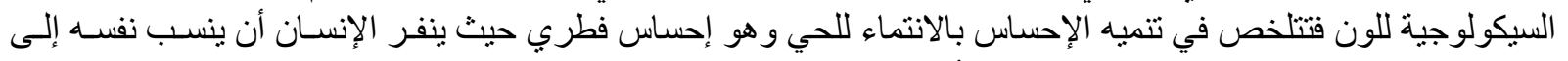

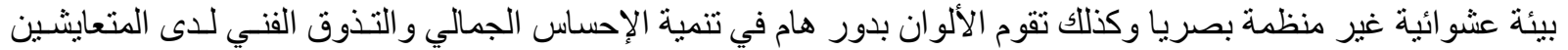
مع الحي السكني، وهو ما ينعكس علي تهذيب سلوكيات الأفر اد قاطني تللك الأحياء.

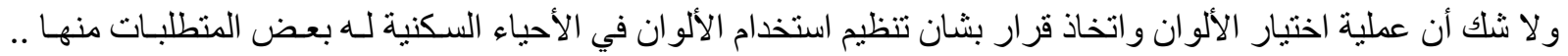

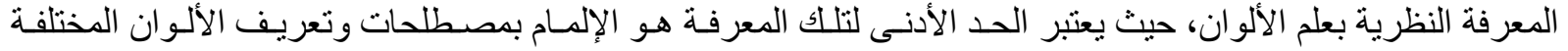

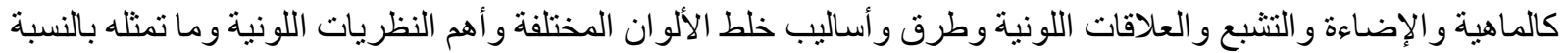

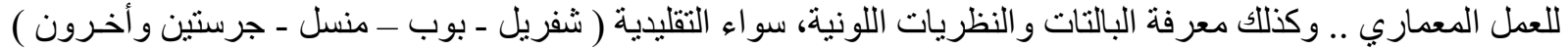

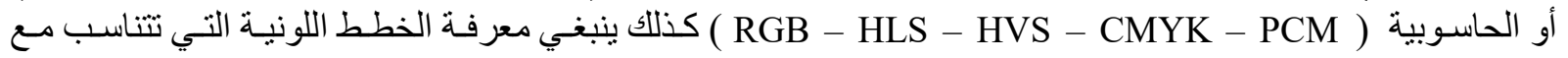

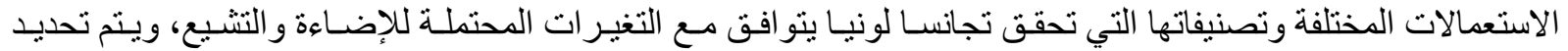

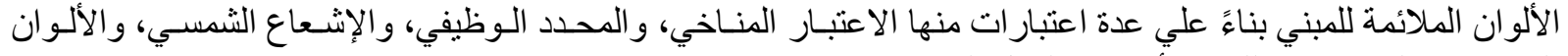

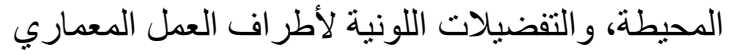

و من هنا تتضح أهمية عنصر اللون لما لله من قوة كامنة وقدرة هائلة علي تغيير ظـاهر التكوينـات و الأشكال وتـأثنير نفسي

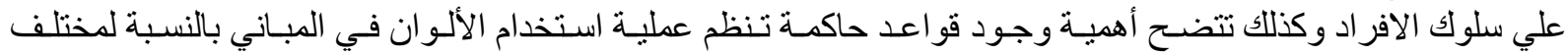




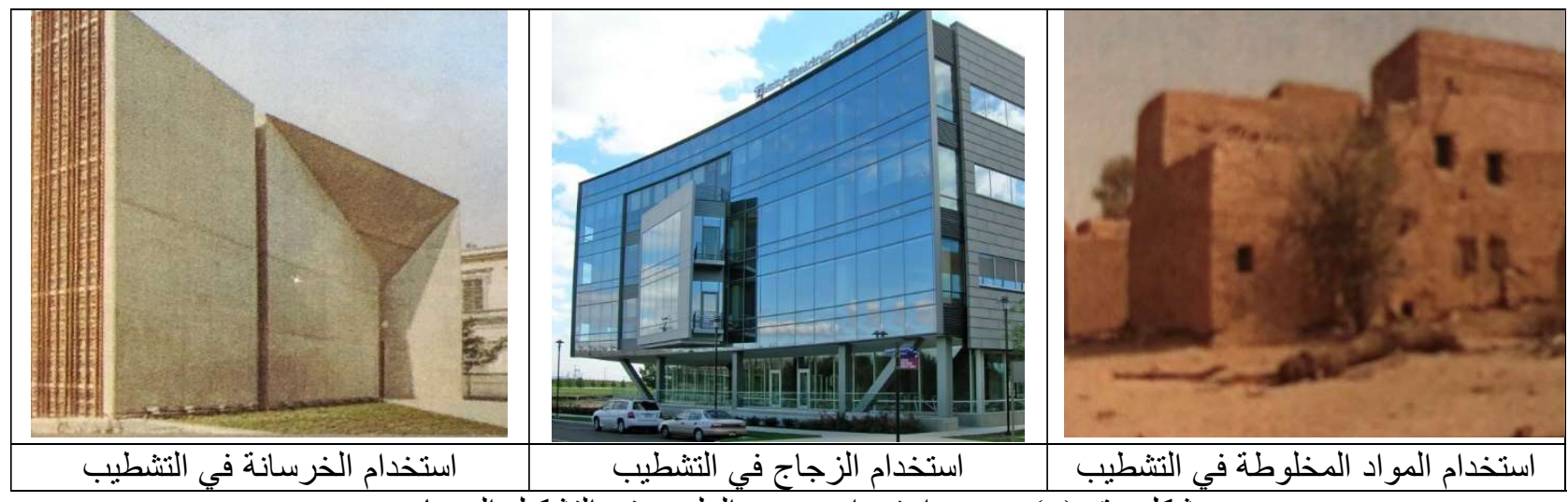
شكل رقم (0) يوضح استخدام عنصر الملمس في التشكيل المعماري

وتعتبر مو اد التشطيب وملمسها ذو أهمية كبيرة في رسم صورة ذهنية للمبني تتعكس علي الأحاسيس سواء بالر احة و الهدو

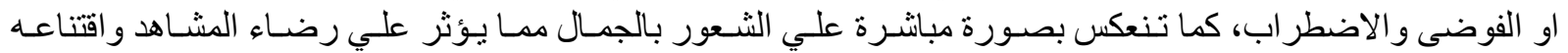

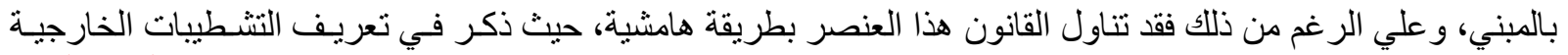

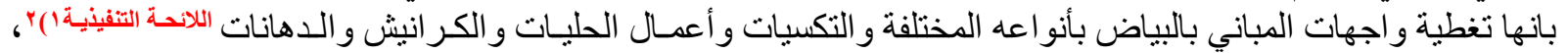

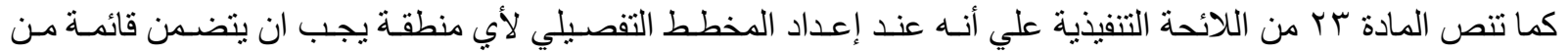

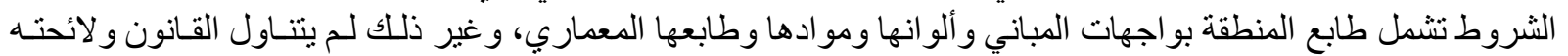

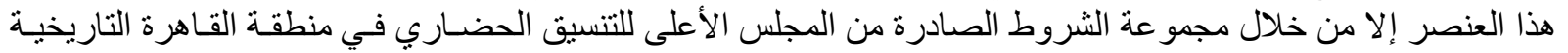

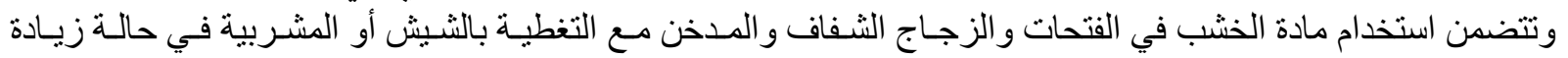

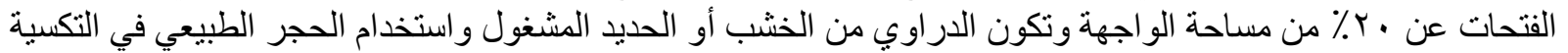

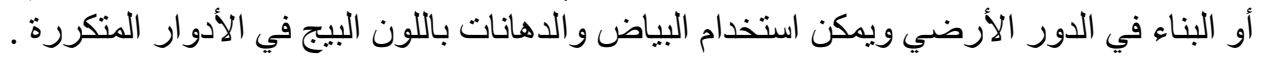

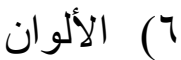

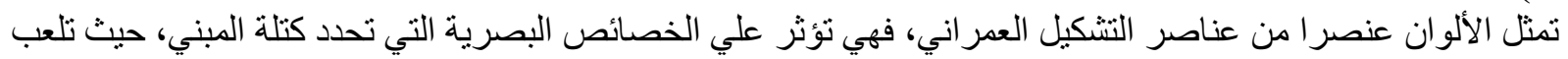

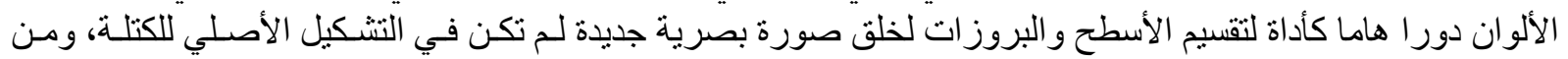

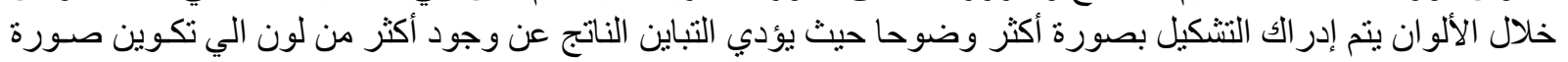

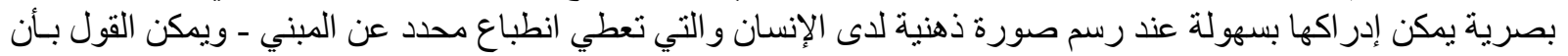

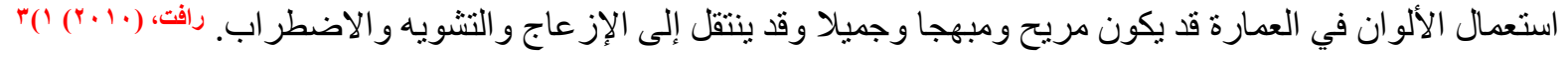

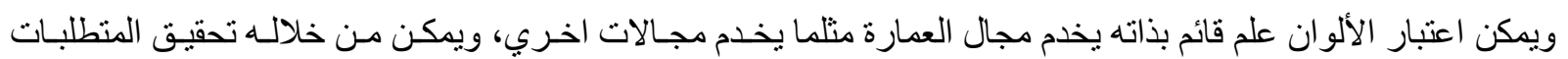

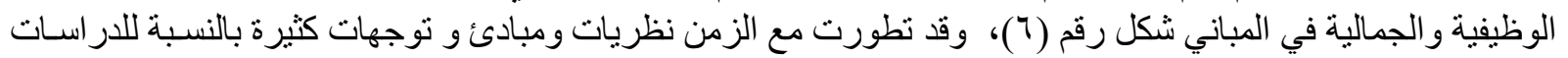

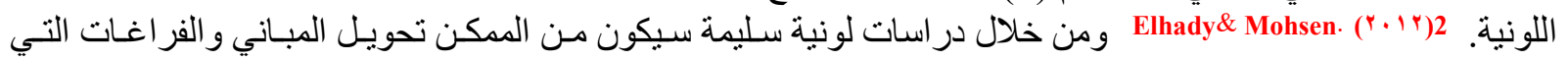

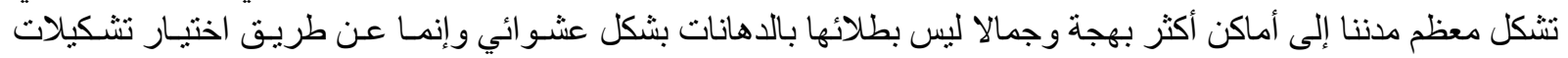

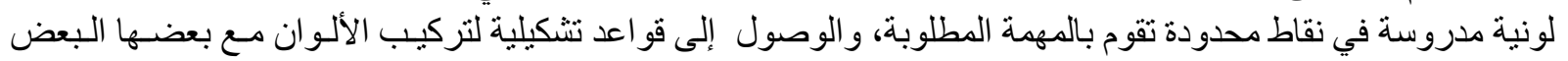
للحصول على أعلى متعة جمالية ممكنة.

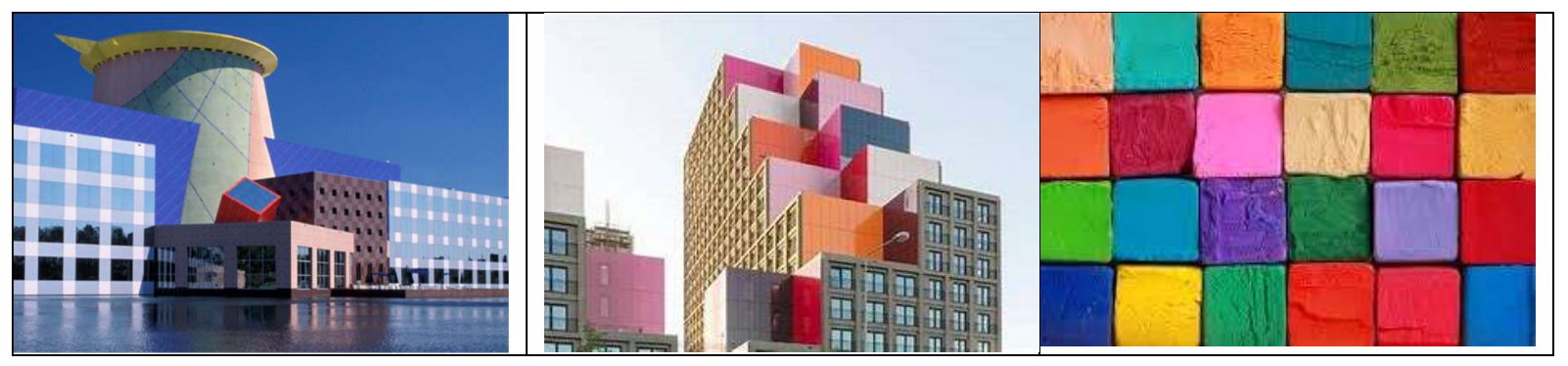




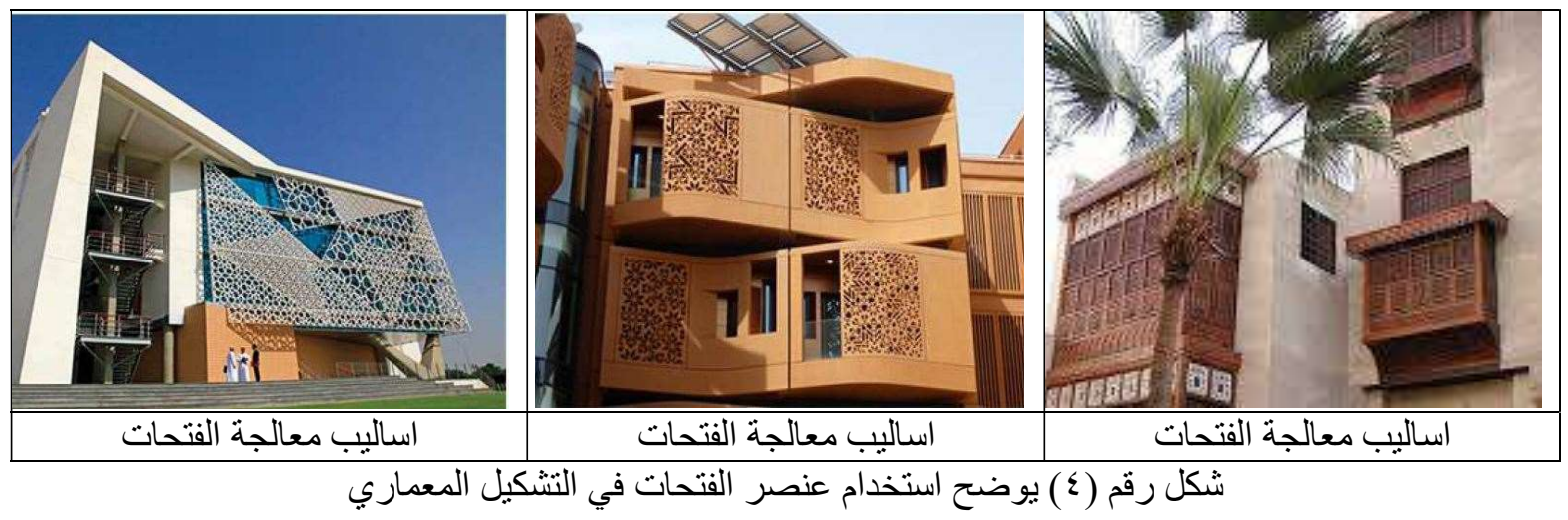

0) الملمس (مواد النهو و التشطيب)

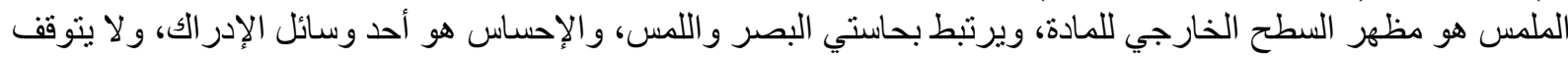

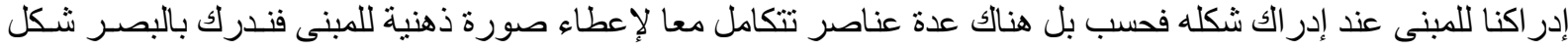

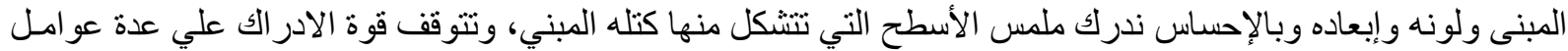

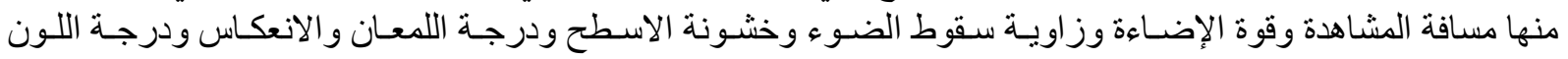
وتشبعه

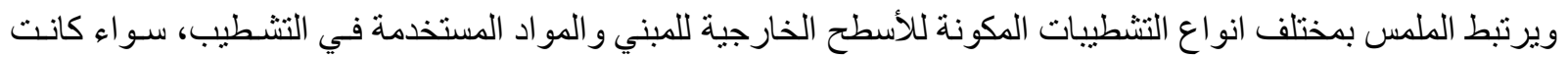

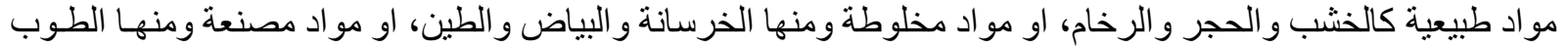

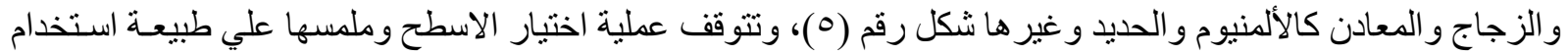

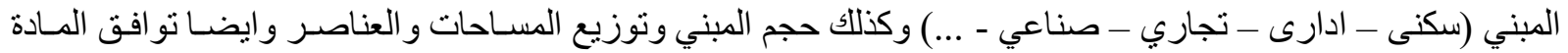

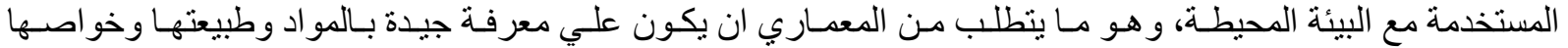
وصورتها المتعددة وامكانيات استعمالها بما يتلاءم مع طبيعة استخدام المبني في محيطة الخارجي.

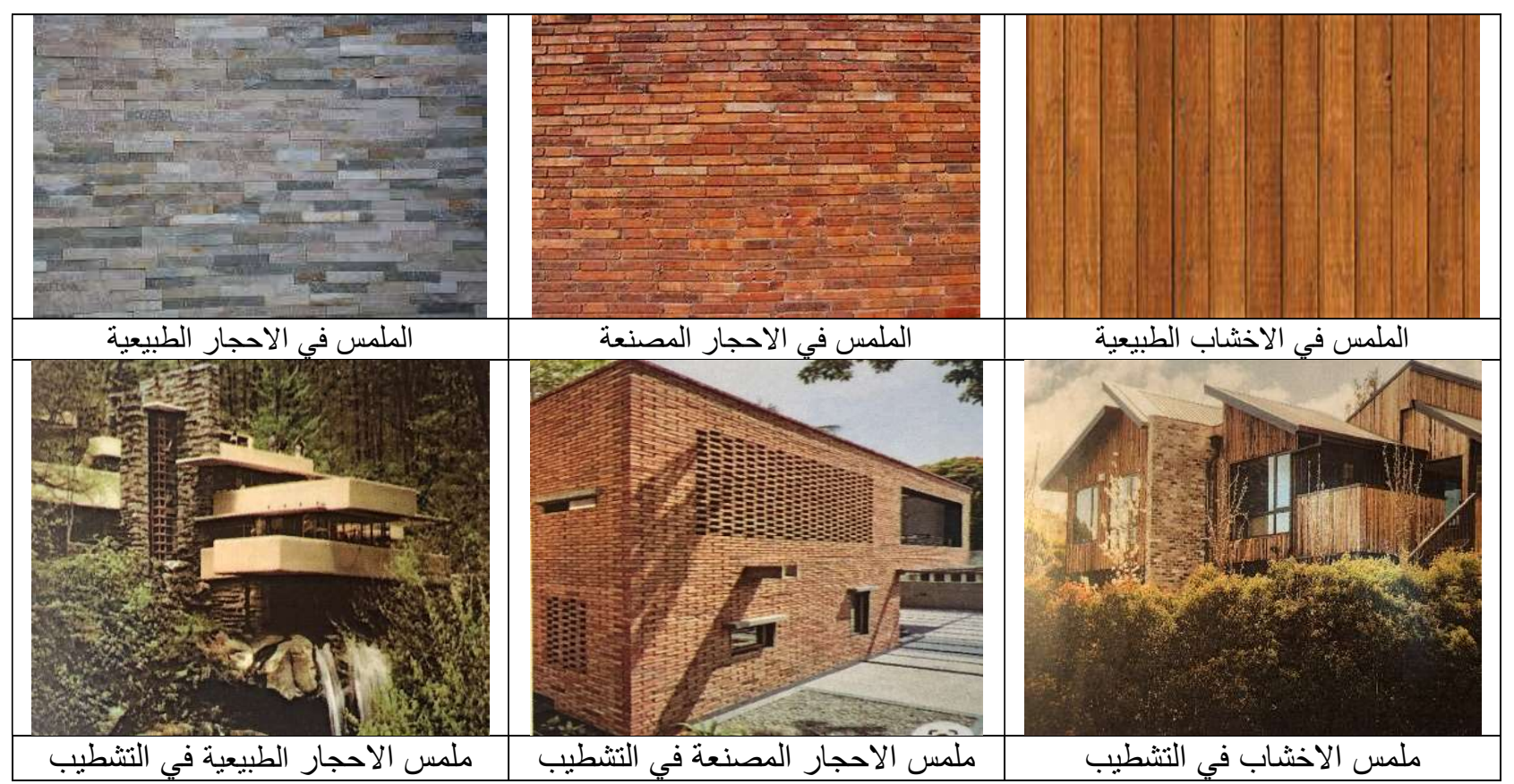


وتتوقف عملية الاستفادة من الفتحة على عدد من المحددات وهي (شكل ومساحة و أبعاد الفتحة ـ اتجاه الفتحـة ـ مـادة تغطيـة وتشطيب الفتحة) وفي بعض الأحيان يتم اللجوء إلى بعض المعالجات لتعظيم الاسـتفادة مـن الفتحـة، منهـا إضـافة كاسـرات الفـات

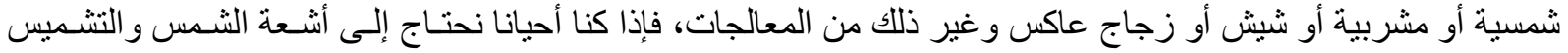

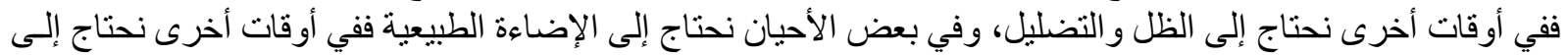

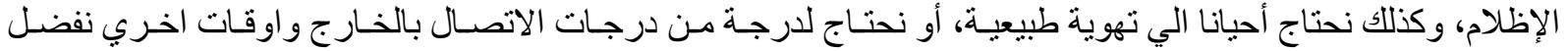

الخصوصية.

هي إذاً مجمو عة من المتغير ات يتحكم فيها المعماري لتحقيق أهداف وظيفية أنثاء تحديد شكل ومسـاحة و وأبعـاد الفتحسة، ومـادة التغطية، ونوع المعالجات المطلوبة تبعا لحاجة الفراغ الداخلي، وكذلك يمكن الاستفادة من الفتحة في التشكيل الخارجي للمبنى.

وتتص المادة 97 من اللائحة التنفيذية للقانون اللانحة التنفيذيةج، علي ألا تقل مساحة الفتحات المخصصة لإضـاءة وتهوية فر اغات

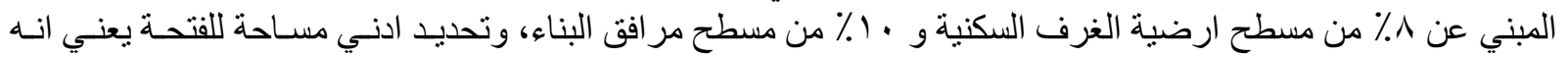

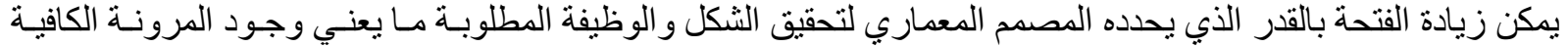

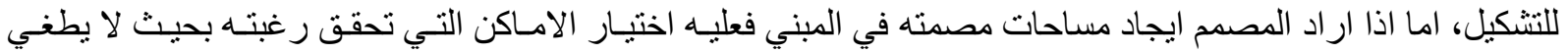

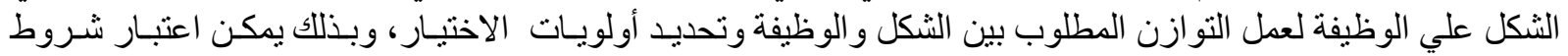
الفتحات الواردة بقانون البناء هي شروط مرنة لتحقيق التشكيل المطلوب في اطار قانوني يحافظ علي عنصر المنفعة.

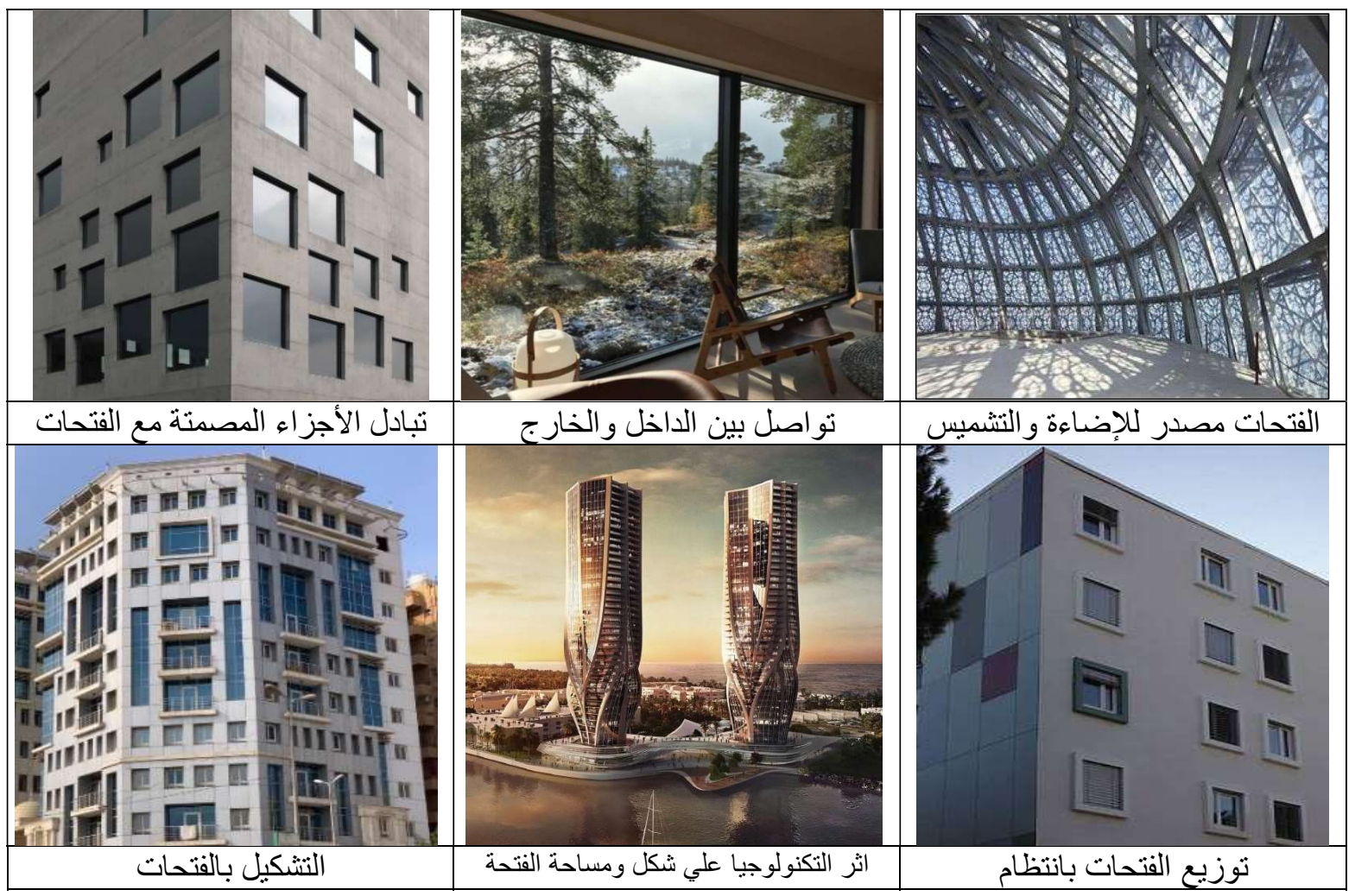




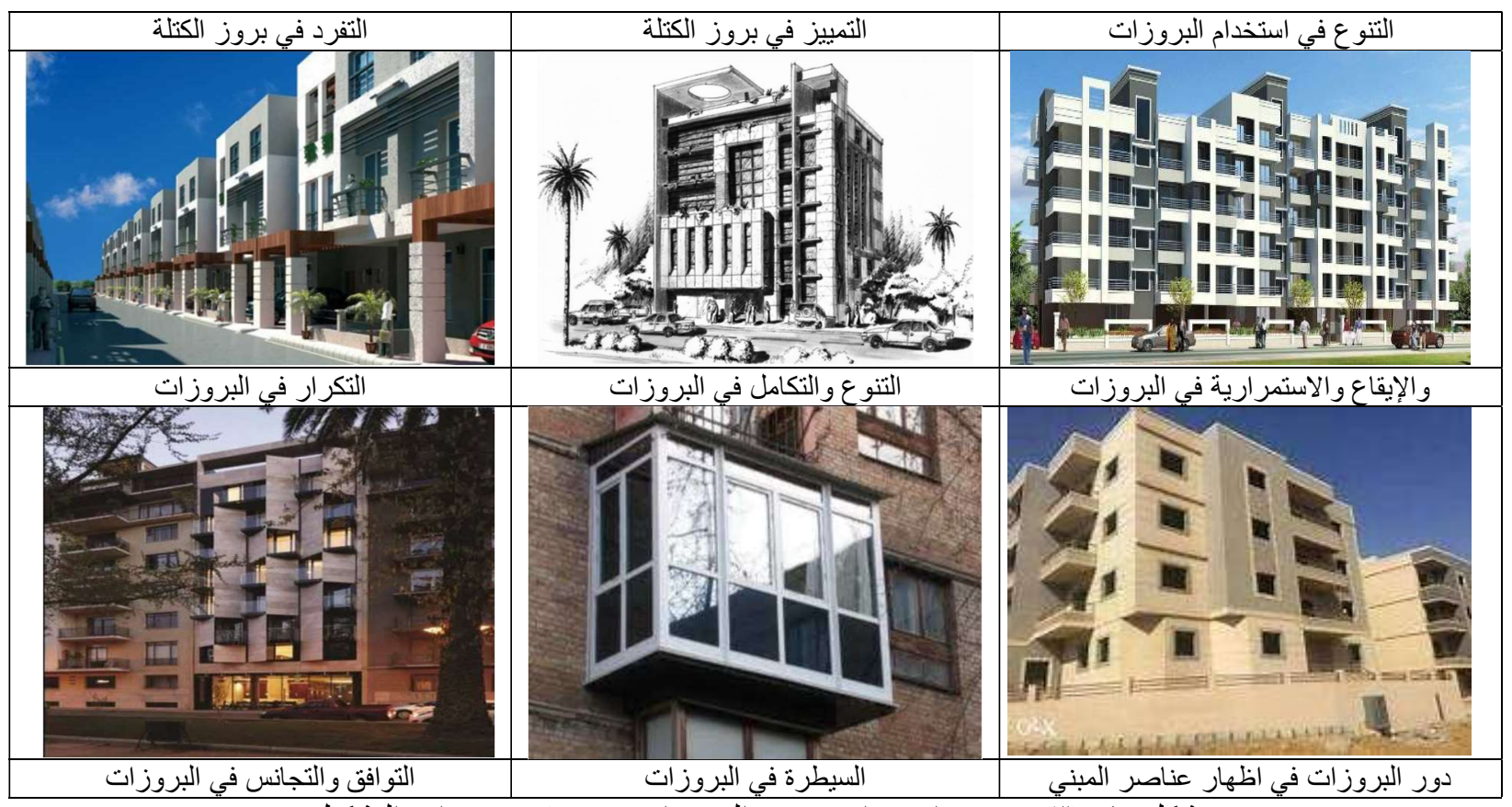

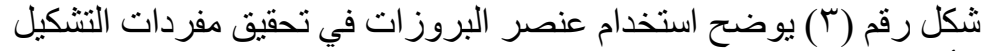

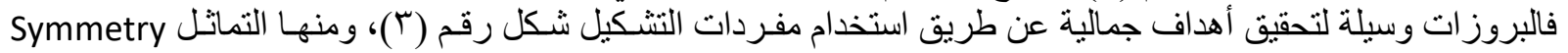

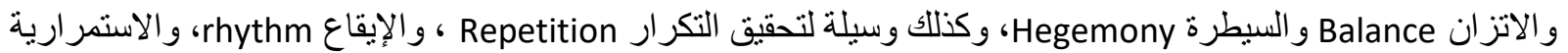

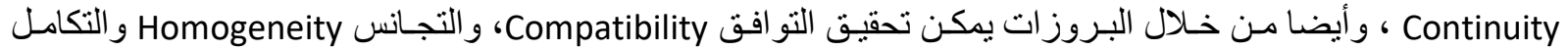

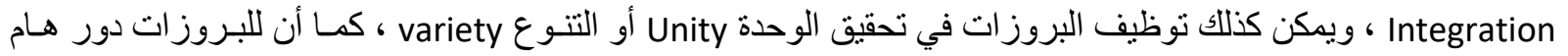

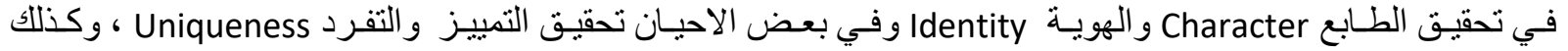

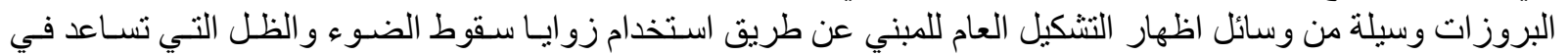

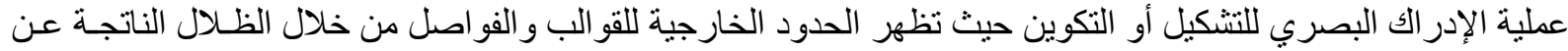

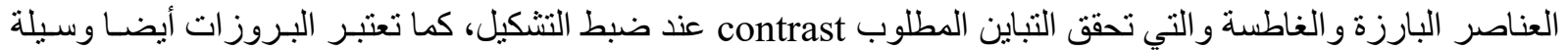

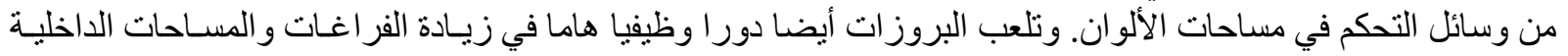

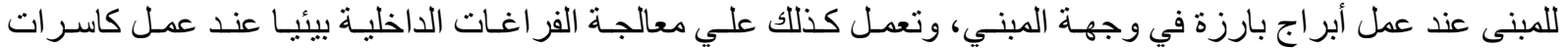

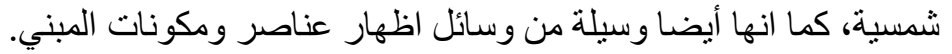

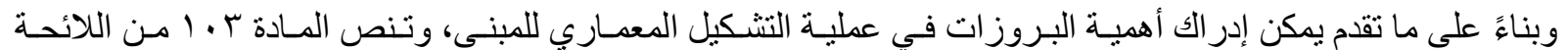

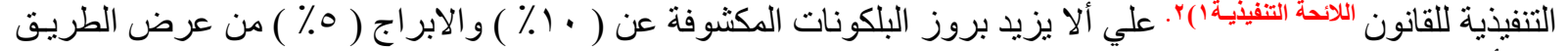

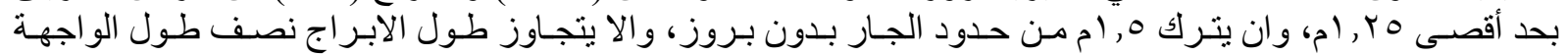

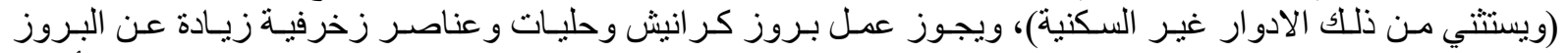

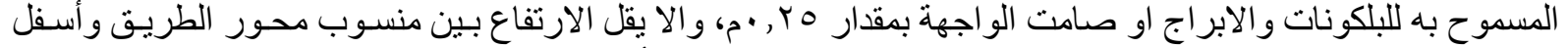
جزء من البروزات عن عم، وتعتبر هذه الثـروط كافيـة لتحقيق الحـد الأدنى مـن المتطلبـات التـي تلبـي مفردات التشـكيل

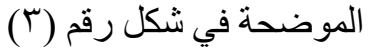

ع ) الفتحات

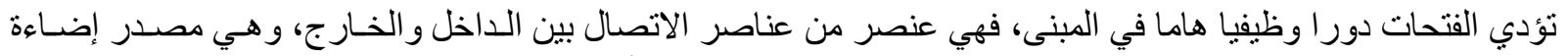

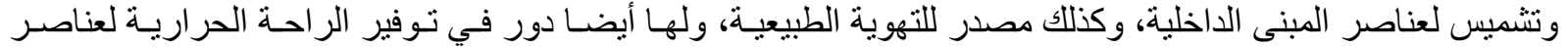

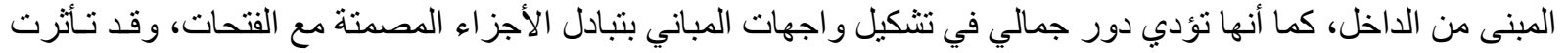

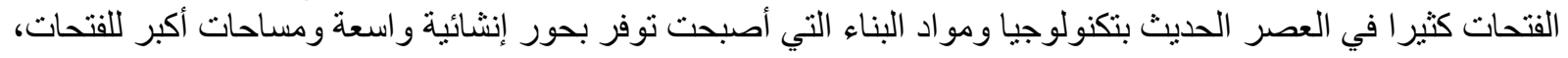

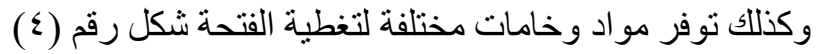


ينطبق الحد الأقصى لحجم المبنى مع الحد الأقصى لهيكل وهمي مسموح بالبناء داخلـه، وهذا يعنـي غيـاب المرونـة الكافيـة

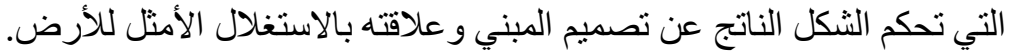

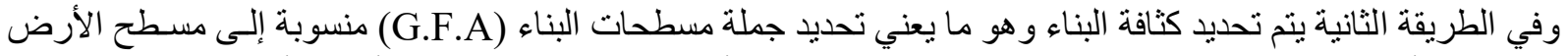

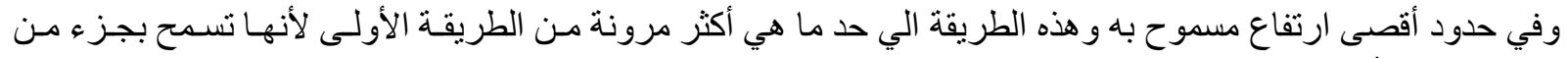

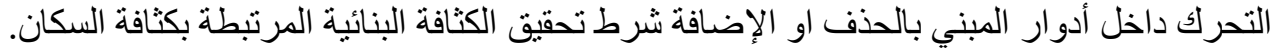

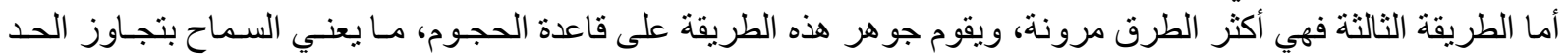

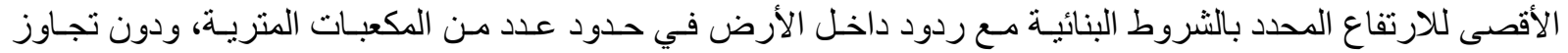

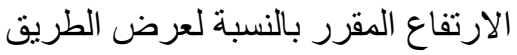

وتعتبر الطريقة الثالثة هي طريقة لترتيب وتنسيق عناصر و أجز اء المبنى في تكوين مرن يلبي متطلبات عمليـة التشكيل مـن

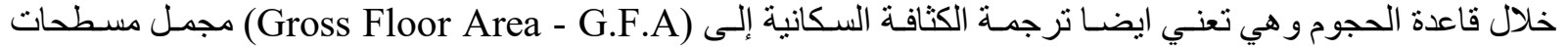

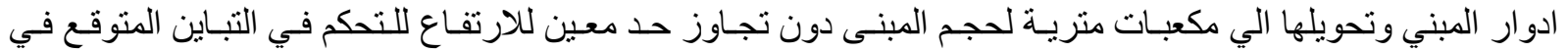

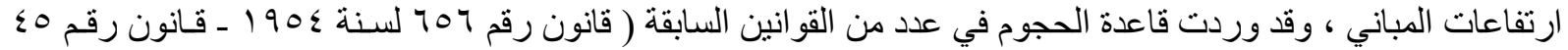

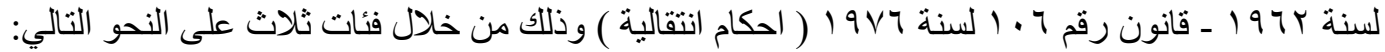

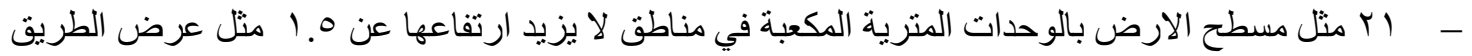

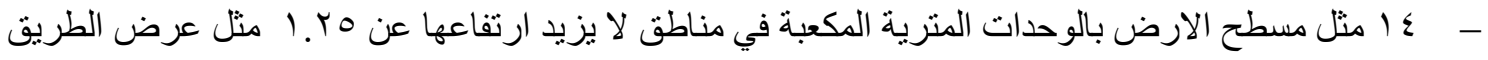

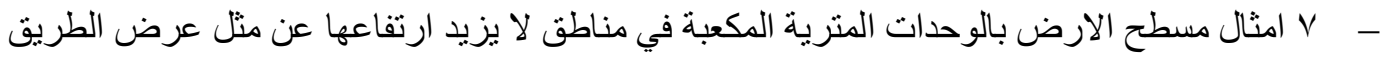

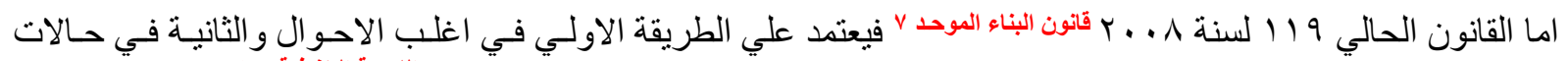

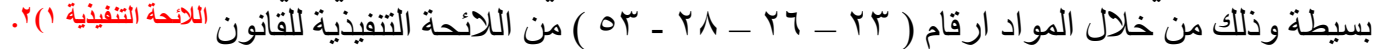

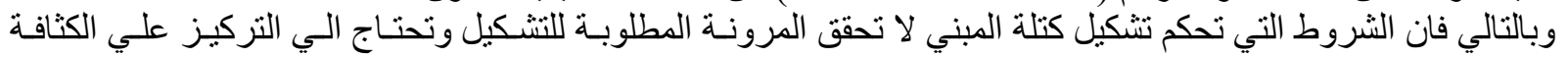
البنائية (F.A.R) في تحديد حجم الكتلة، وكذللك اعتماد قاعدة الحجوم كأحد الاساليب الني تحقق المرونة المطلوبة للتشكيل.

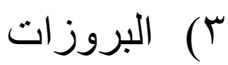

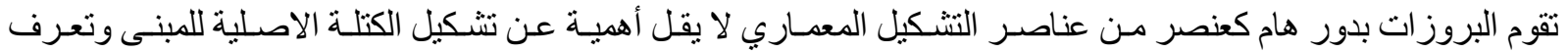

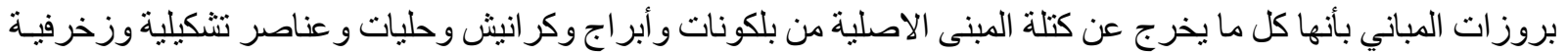
وتعتبر هذه البروز ات أداة من الأدوات المؤثرة بصورة قوية في تشكيل المبنى لما لها من أهداف وظيفية وأهداف أهداف جمالية.

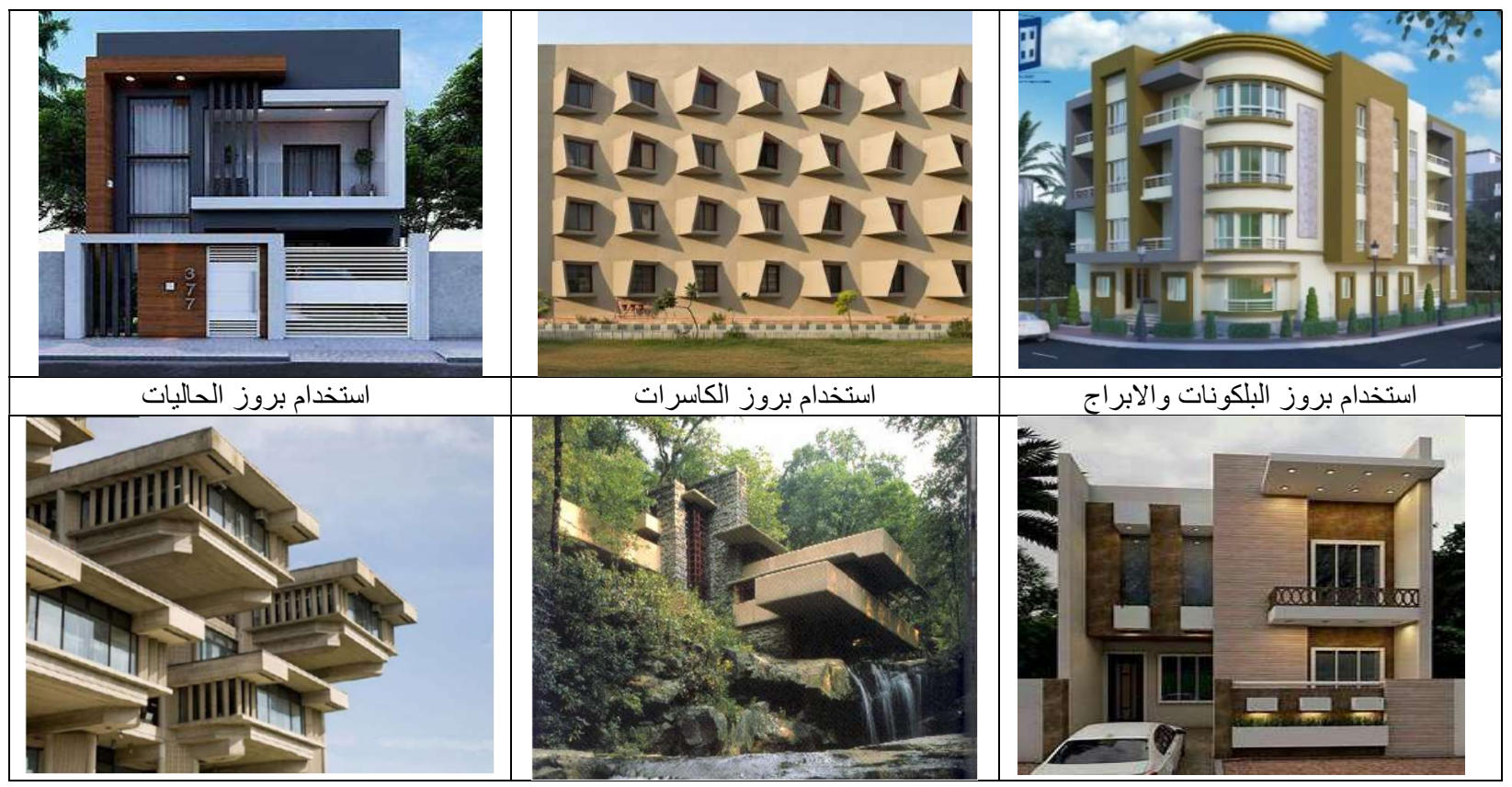




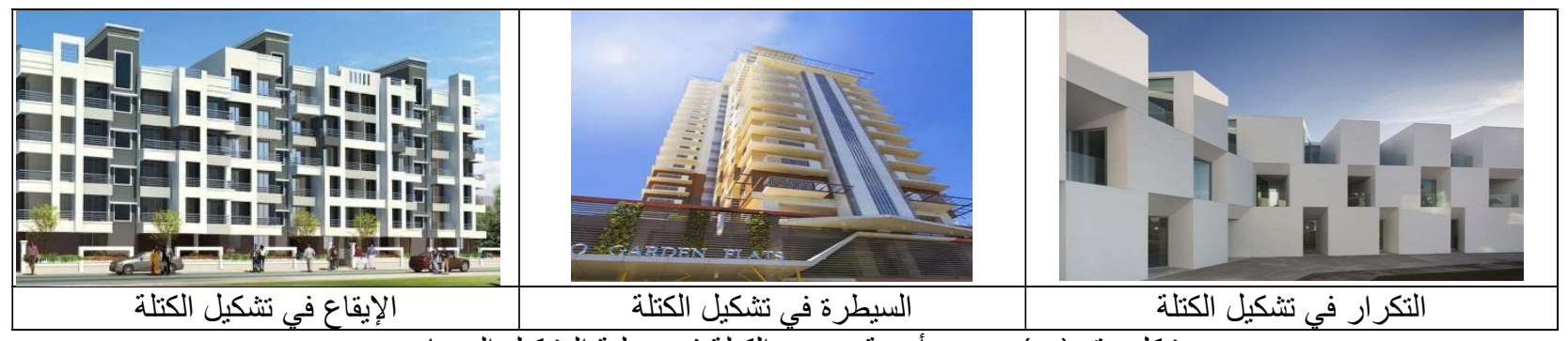

شكل رقم (1 ) يوضح أهمية عنصر الكتلة في عملية التشكيل المعماري

أما حجم الكتلة فهو في الأساس بعتمد في تحديده على كثافة السكان المستهدفة الواردة في المخطط الاستر اتيجي العام للمدينة

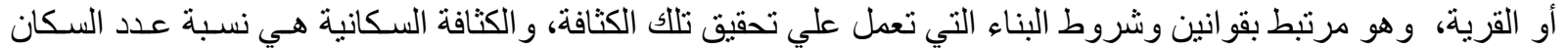

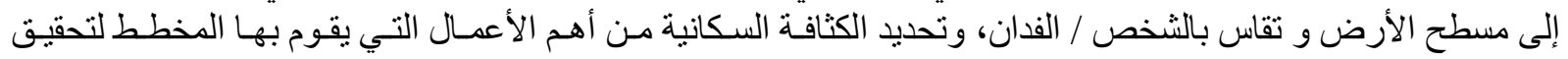
التو ازن بين عدد السكان وبين المر افق العامة وكذلك الخدمات التي توفر لهم بالمنطقة، ويتم التحكم في الكثافـة السكانية عن التصن

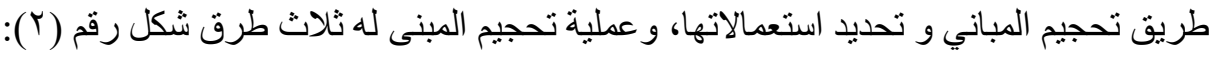

\begin{tabular}{|c|c|c|c|c|}
\hline \multicolumn{3}{|c|}{ الاشكال الناتجة عن الطرق المختلفة لتحجيم المبني } & 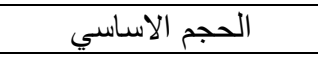 & \multirow{2}{*}{ 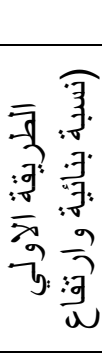 } \\
\hline ثبات الثكل من مبني لمبني & ثبات الثكل من مبني لمبنى & محدد بارتفاع الدور مع نسبة اشغال & هيكل افنتر اضي طبقا لكثافة السكان & \\
\hline تغبر الثنل مع ثبات الكثافة & تغير الشكل مع ثبات الكثافة & محدد بكثافة بنائية & هبكل افتر اضيى طبقا لكثافة السكان & 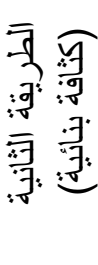 \\
\hline & & & & 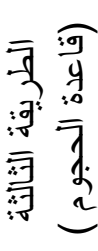 \\
\hline تغبر الشكل من مبني لمبني & تغير الثكل من مبني لمبني & مكبات مباني (ب مثل مسطح الارض & هيكل افتر اضي طبقا لكثافة السكان & \\
\hline
\end{tabular}

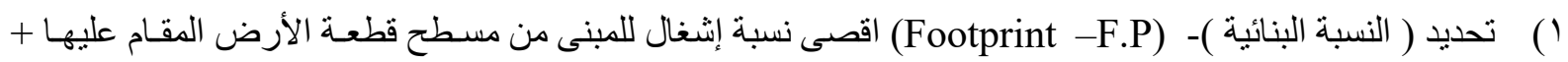

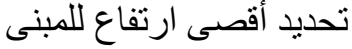

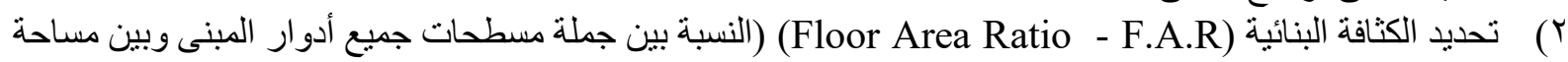
قطعة الأرض المقام عليها المبنى)

r) ت تعيين حجم مكعب المباني على أساس الوحدات المترية مضروبة في مسطح قطعة الأرض ( قاعدة الحجوم ) فالطريقة الأولى يتم تحديد هيكل الكتلة داخل إطار ثابت، عبارة عن هيكل وهـي محدد بمسـاحة مـن الأرض للبنـاء عليها

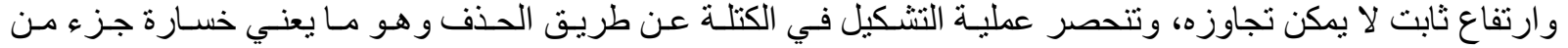

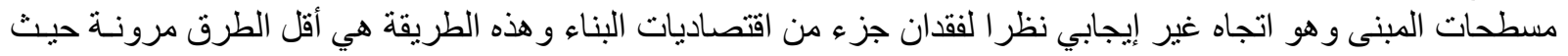




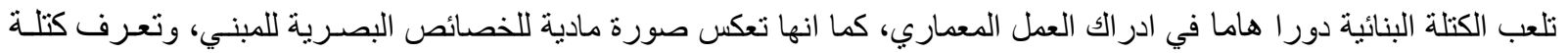

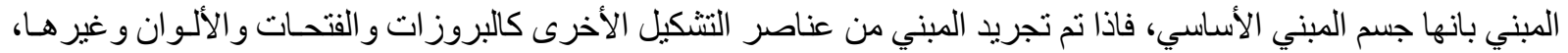

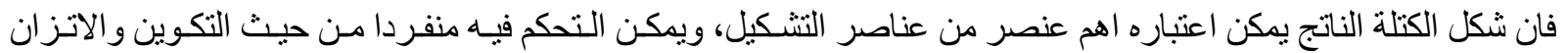

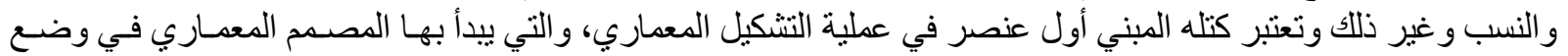

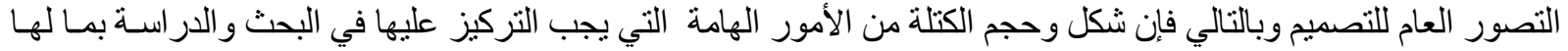
من بالغ التأثنير في عملية النتكيل المعماري

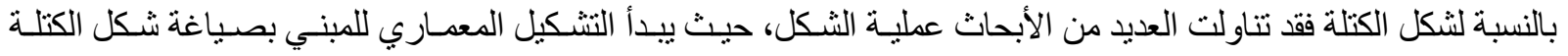

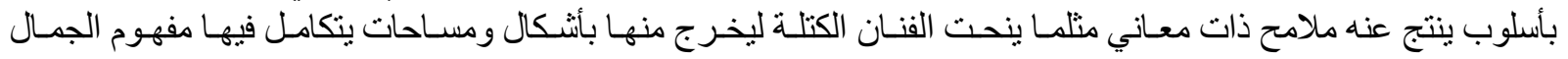

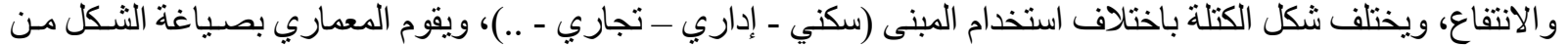

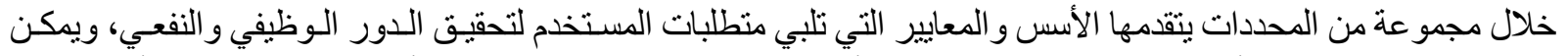

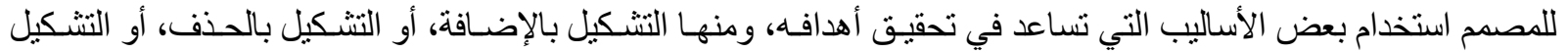

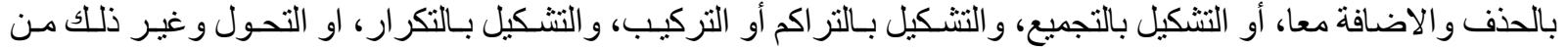

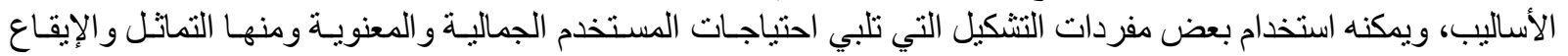

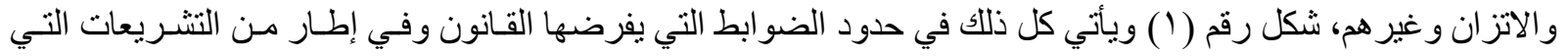
تحكم المباني والعمر ان.

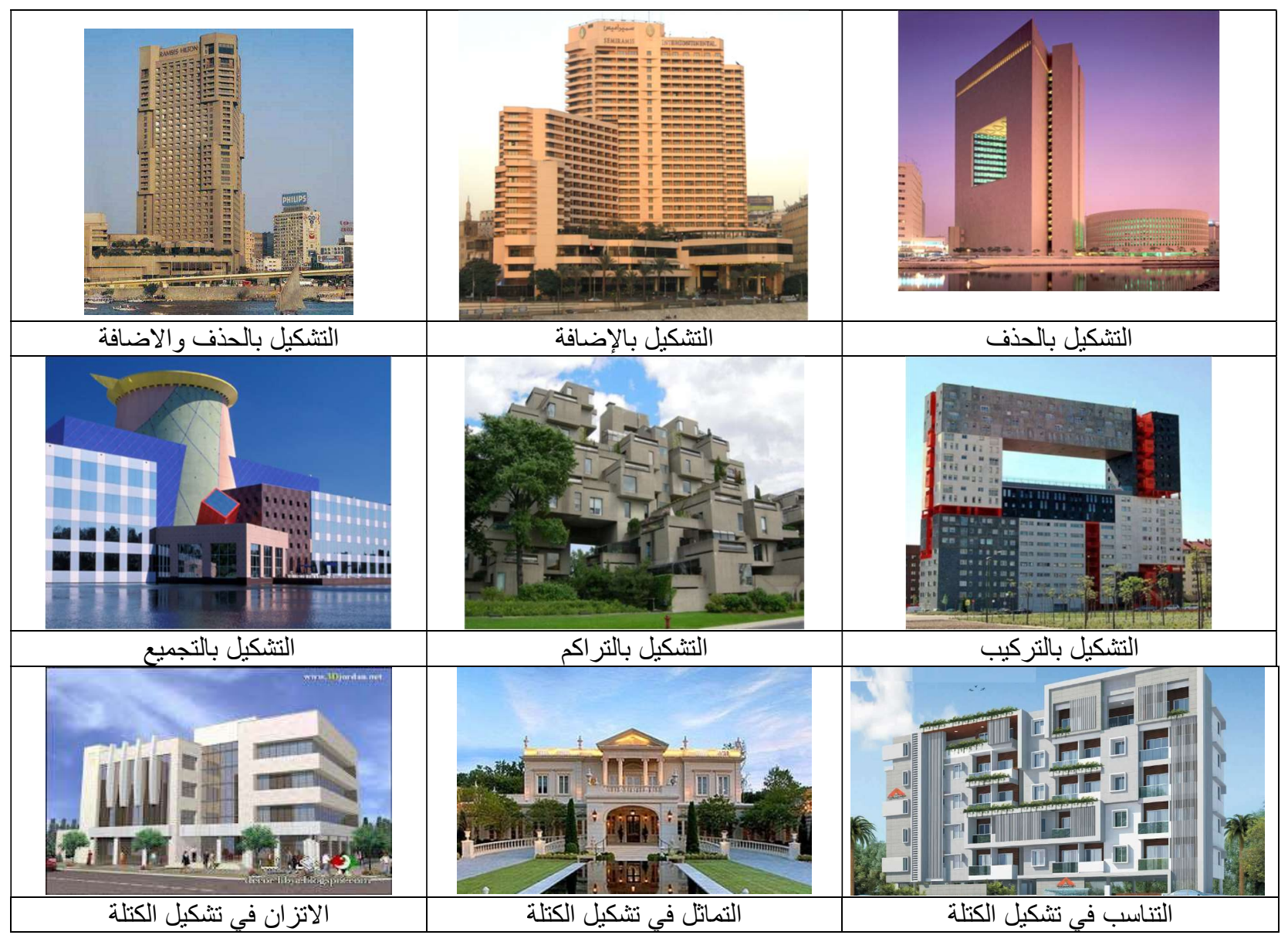


يعتمد البحث في الأساس على منهج التفسير النقدي ( Critical Interpretation ) الذي يهدف إلى حل مشكلة التوازن بين

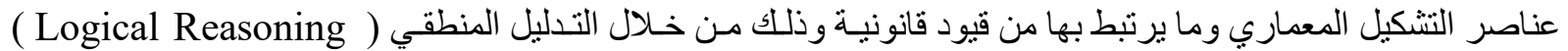

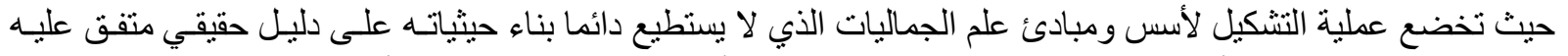

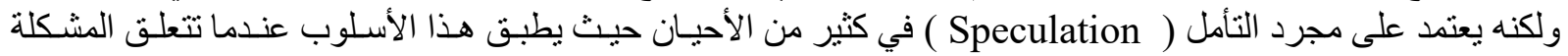

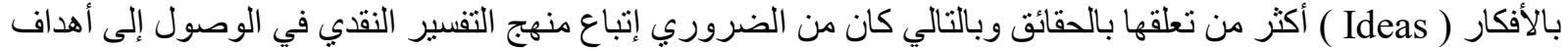

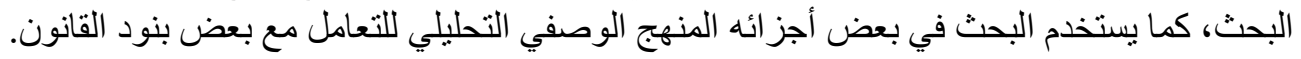

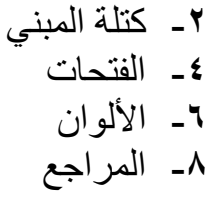

عناصر البحث

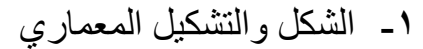

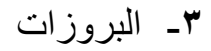
•- م- الملمس (مواد النهو و التشطيب)

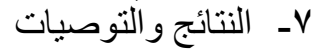

( ) ) الثكل و التشكيل المعماري

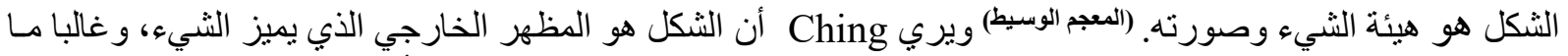

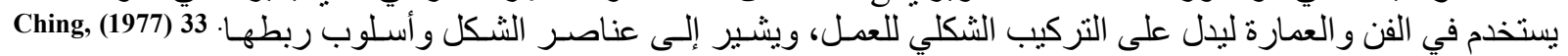

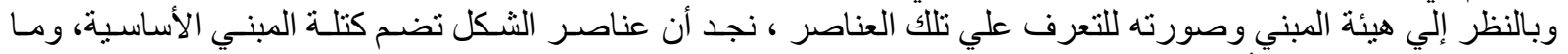

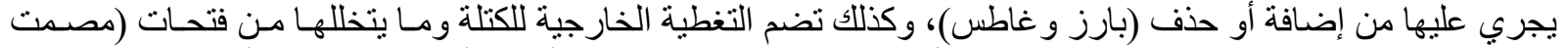

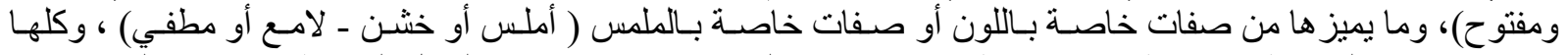

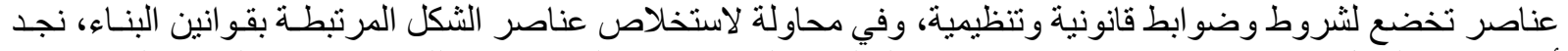

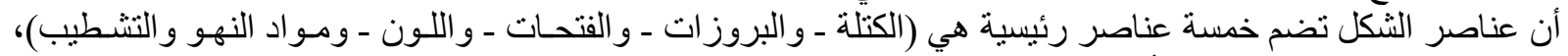

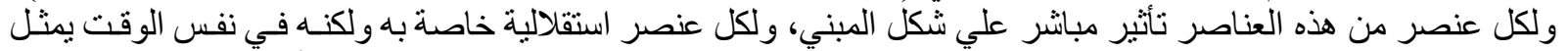

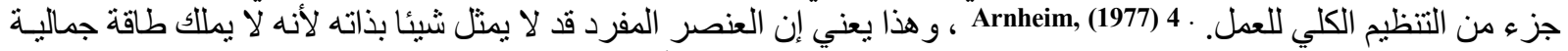

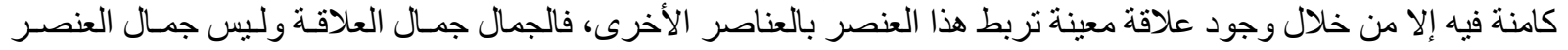

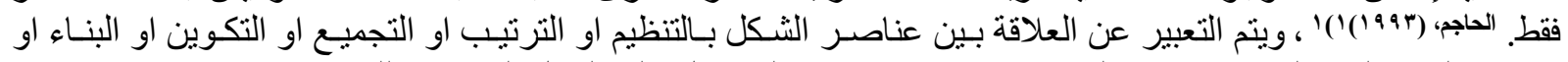

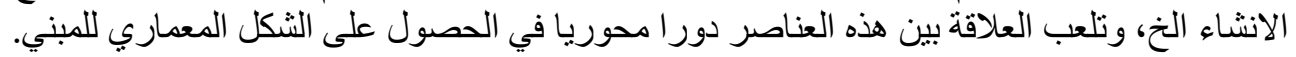

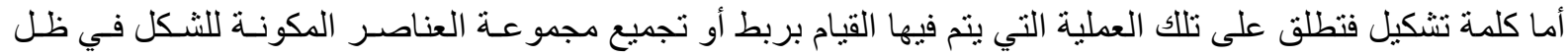

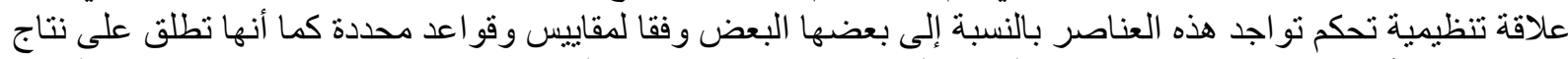

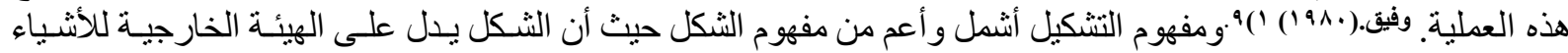
فقط بينما مفهوم التثكيل يذل على التحكم في (الهيئة الخارجية للأشياء) بالتنظيم والتوجيه للحصول على الثكل الأفضل.

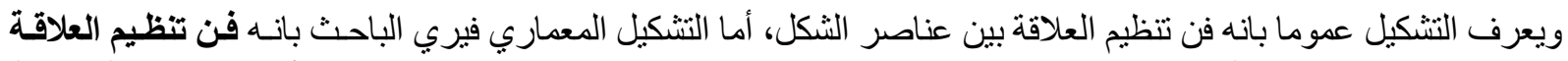

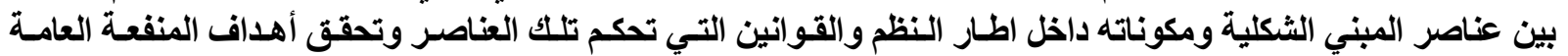

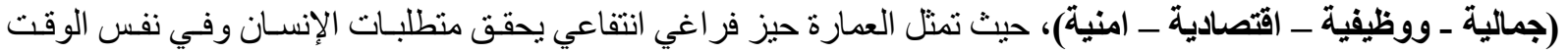

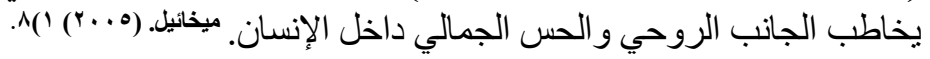

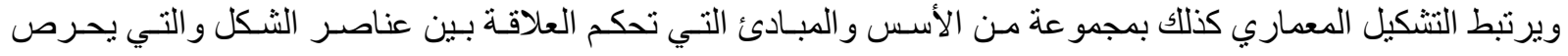

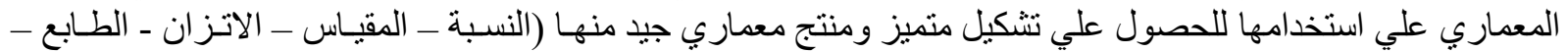

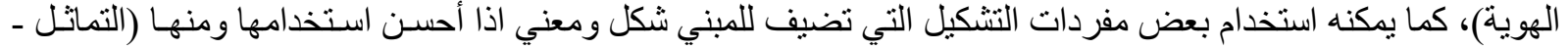

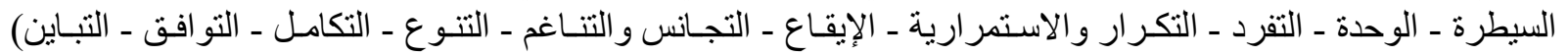

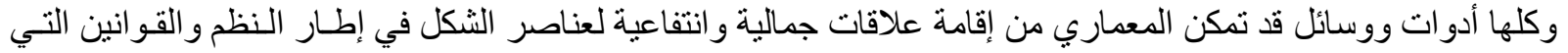

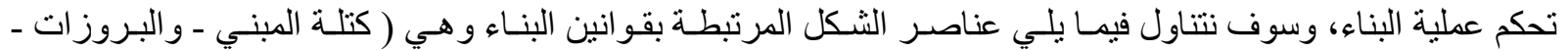
و الفتحات ـ و اللون - ومواد وسناء النهو والتنشيب). 


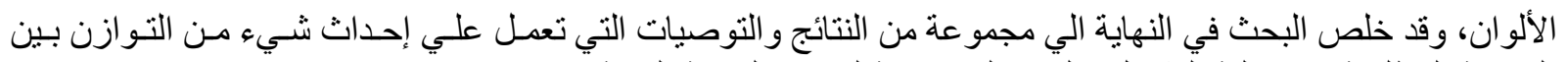
المرونة المطلوبة في عملية التنشكيل و القيود المفروضة النية لتحقيق المنفعة العامة.

الكلمات المفتاحية: التشكيل المعماري، الثكل، الكتلة، الملمس، اللون، قوانين البناء.

المقدمة

عندما يمتلك المعماري خيالاً واسعاً وحرية كاملة بدون أي قيود قد تحد مـن تطلعاتـه في التشكيل المعمـاري للمبنى .. فقد

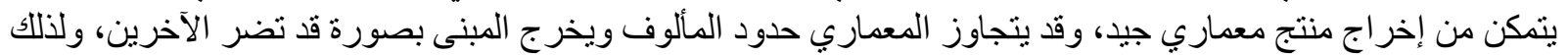

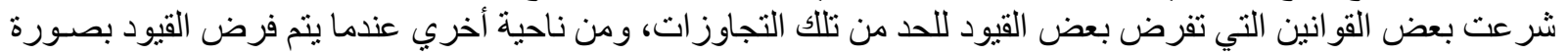

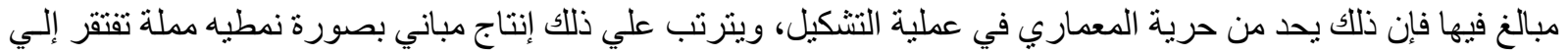
النو احي الجمالية.

وقال الفيلسوف اليوناني "Heraclitus "إن مشكلة المجنمع تنحصر في كيفية جمع .. تللك الدرجة مـن القانون و التي بـدونها

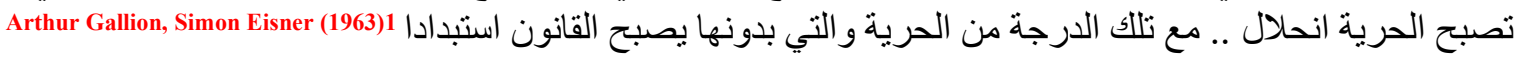

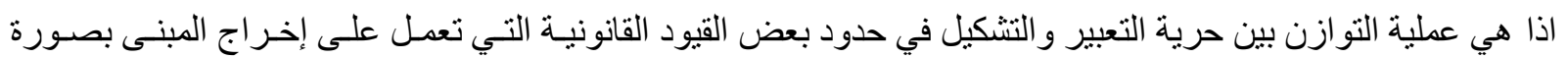

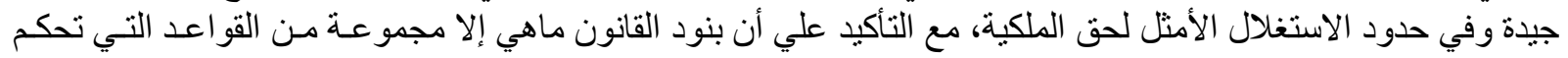
أعمال البناء بطريقة شرعية لتحقيق الصالح العام.

المشكلة

أن التوازن بين حرية التشكيل المعماري و القيود التي تفرضها قو انين البناء هو توازن مفقود إلى حد ما، حيث تظهر المشكلة

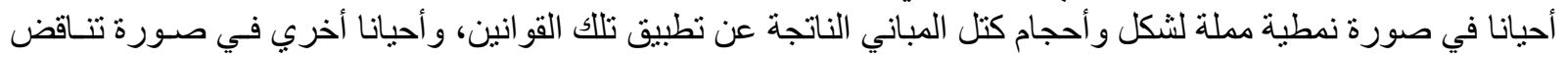

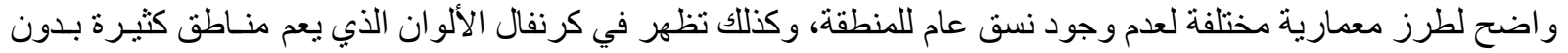
أي قيود تحكم تنظيم واختيار الألوان. فرضية البحث

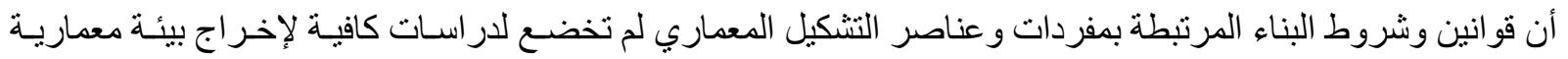

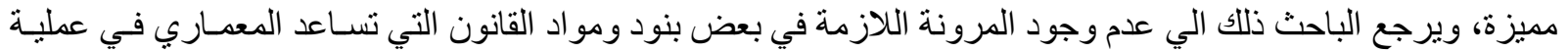

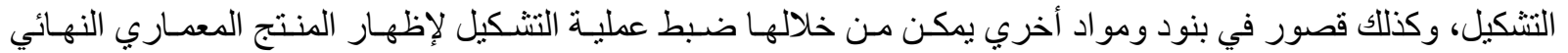

بصورة أفضل. أهمية البحث

• يتناول البحث التشكيل العمر اني كأحد المتطلبات الرئيسية لتحسين البيئة العمر انية.

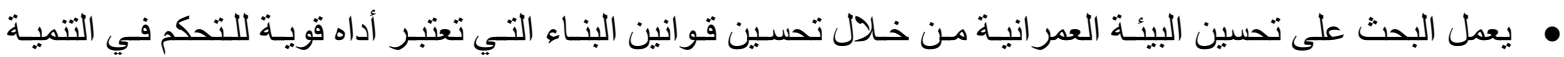

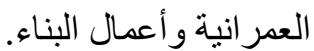
• يعمل البحث على زيادة استخدام حق الملكية وتصحيح مسار القانون لتحقيق المرونة المطلوبة في التشكيل المعماري. الأهدف من البحث الهدف الرئيسي من البحث هو إيجاد نو إن بان بين التشكيل المعماري للمباني، وبين القيود التي تحكم عملية التشكيل الناتجة عن

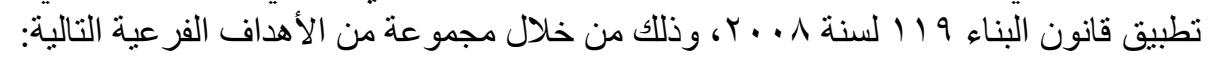
• التعرف علي عناصر ومفردات التشكيل المعماري التي ترنبط بمو اد وبنود قانون البناء.

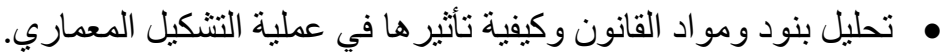
• تحديد مو اطن الضعف و القصور القانونية ومحاولة إيجاد الحلول اللازمة لتحسين الصوري الصورة البصرية للمباني. 


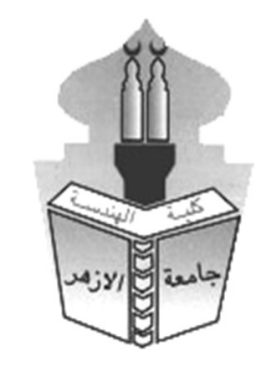

\title{
FLEXIBILITY OF ARCHITECTUR FORMING AND RESTRICTIONS OF BUILDING LAW
}

\author{
Ahmed Saad Dabour \\ Architecture Department, Faculty of Engineering, Al-Azhar University, Cairo, Egypt. \\ Author E-mail: dr.dabour@azhar.edu.eg
}

Received: 03 May 2021 Accepted: 07 June 2021

\begin{abstract}
:
Many studies talked about the architecture forming elements and its importance in the building's shape, The architecture forming is the extraction of the designer's ideas about making the buildings at its shape using the designing basics, principles and elements to reach to the building at the wanted shape, at the same time he is obligated to the law that controls the building process. The research is talking about the study of these elements and how flexible is the law in dealing with it, this is study contains the main forming elements like the building's mass and the restrictions related to it like height, area, It also contains prominence element, openings element, colors element, and the Texture element through studying the finishing materials. In the end the research achieved a pack of results and recommendations that makes a balance between the needed flexibility in forming and law restrictions to reach to general benefit.
\end{abstract}

KEYWORDS: Architecture forming, shape, mass, texture, color, building law.

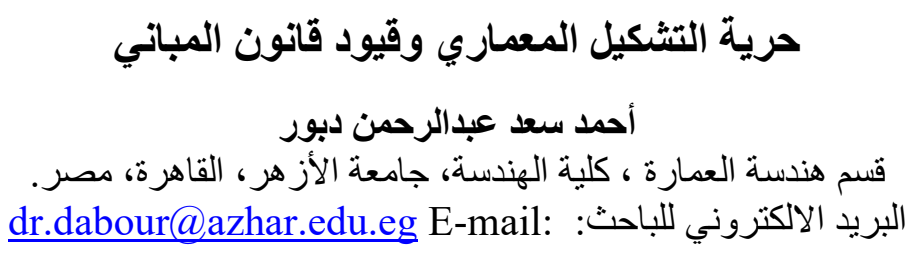

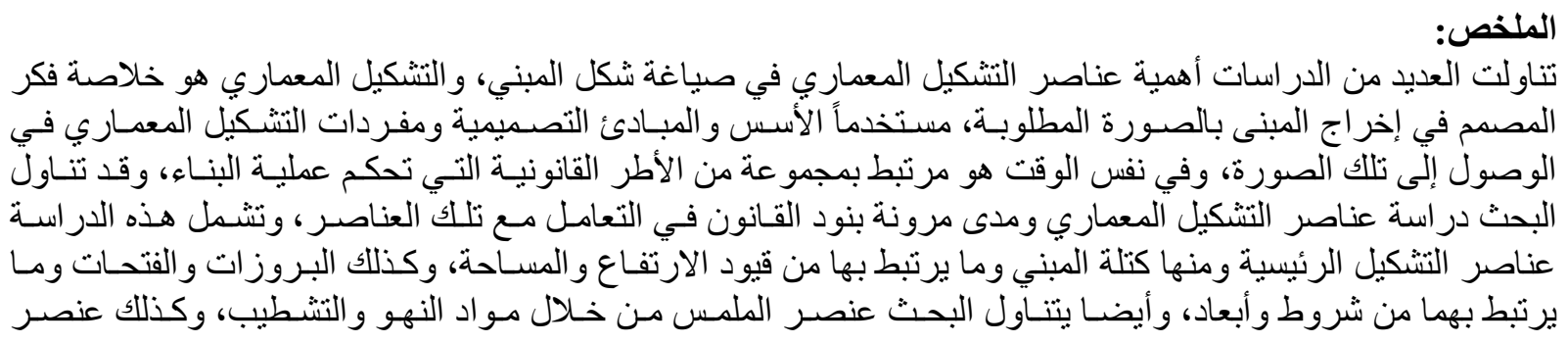

